\section{Cronología de las relaciones interétnicas de los pehuenches fronterizos del siglo XVIII}

Chronology of interethnic relationships of bordering Pehuenches in the $18^{\text {th }}$ Century

\section{Oscar S. TORO-BARDECI*}

\section{Resumen}

Se consultaron fuentes y documentos escritos desde fines del siglo XVII hasta principios del XIX para reconocer las estrategias culturales y políticas expresadas en los parlamentos hispano-indígenas de la frontera del Biobío, mediante las cuales los grupos pehuenches del siglo XVIII lograron mantener su particularidad como entidad social. Su movilidad y conocimiento de las rutas y pasos

\footnotetext{
Investigación enmarcada en el proyecto FONDECYT $\mathrm{N}^{\circ}$ 1120857 "Expresión y presencia del otro en la frontera araucana: inscripciones mapuches e hispanas en lugares y en relatos de parlamentos de tres área de la Araucanía colonial, 1605-1803". Responsable: José Manuel Zavala Cepeda

** Mg en Historia y Arqueólogo, Sociedad Chilena de Arqueología. osctoro@gmail.com
}

transcordilleranos fueron claves culturales que dicha agrupación aprovechó tanto para acceder a los flujos comerciales fronterizos y controlar el acceso hacia las salinas y vegas orientales, como para formar alianzas políticas con los españoles. Se propone una cronología para las relaciones hispano-pehuenches en el siglo XVIII, desglosada en cinco momentos claves que caracterizaron dicha relación interétnica y donde se aprecian los cambios acaecidos a lo largo del período analizado, ante un panorama social complejo desde el punto de vista político y económico.

Palabras claves: pehuenches coloniales, frontera del Biobío, parlamentos hispanoindígenas, transferencias culturales

\section{Abstract}

With the aim of recognize cultural and political strategies developed by Pehuenches groups in the Spaniard-Indigenous Conferences of $18^{\text {th }}$ Century in Biobío border, I accessed to archives and several documents wrote between late $17^{\text {th }}$ and early $19^{\text {th }}$ centuries. In such political meetings it can be seen how Pehuenches kept their particularity as a social entity distinguish from the Mapuches. On the one hand, their mobility and knowledge of the Andean walkways was the key to access to border commercial flow and, on the other hand, to control over eastern salt mine and meadows, establishing political alliance with Spaniards. It is proposed a chronology for Spaniard-Pehuenche relations in the $18^{\text {th }}$ Century, through five specific moments which are considering as landmarks in this interethnic relation, and from where it can be distinguish the changes throughout this whole period. These 
changes refers to a complex social reality, with political and economic consequences.

Key words: colonial Pehuenches, Biobío border, Spaniard-Indigenous Conferences, cultural transfers

\section{Antecedentes}

Ante la pregunta de cuáles fueron las estrategias culturales que pusieron en práctica los habitantes de la cordillera andina en el marco de las relaciones interétnicas fronterizas en la frontera del Biobío en el siglo XVIII, se responde hipotéticamente que los pehuenches desplegaron estrategias centradas en el control sobre ciertos recursos claves (ganado y sal) aprovechando su conocimiento del territorio, lo que les permitió distinguirse como grupo étnico aprovechando dichas variables para posicionarse de manera preponderante dentro de las relaciones interétnicas que se desarrollaron en el mundo fronterizo del siglo XVIII. En ese contexto, su movilidad y conocimiento de las rutas y pasos transcordilleranos fueron claves culturales que aprovecharon dichas agrupaciones para acceder tantoalosflujos comerciales fronterizosy controlar el acceso hacia las salinas orientales, como para formar alianzas políticas con los españoles. Como planteamiento complementario, se afirma que las poblaciones pehuenches del siglo XVIII se vieron incluidas en un doble proceso de "transferencias culturales": por un lado, desde los hispanocriollos, con quienes se relacionaban en términos de intercambios $\mathrm{y}$, por otro lado, los mapuches del valle occidental, quienes habían extendido sus territorios hacia el este, incluyendo la cordillera andina y las pampas. Dichos procesos y posicionamientos serían posibles de identificar de manera particular en los parlamentos hispano-indígenas en que participaron los grupos pehuenches (Toro 2015: 7-8).

Explicitada la problemática e hipótesis de trabajo, se plantean a continuación los pasos metodológicos y objetivos, junto a una breve caracterización histórica y definición de conceptos teóricos aplicables a los grupos pehuenches coloniales, para posteriormente exponer y analizar los datos recolectados en torno a los objetivos planteados, los que servirán para una discusión que ponga en perspectiva la propuesta inicial, concluyendo ciertos aspectos necesarios de recalcar y que quedarán pendientes para futuros trabajos sobre la temática.

\subsection{Metodología y objetivos}

Se consultaron fuentes manuscritas ${ }^{1}$ e impresas, específicamente diferentes documentos escritos desde fines del siglo XVII hasta principios del XIX (p. ej. De la Cruz 1953 [1806], Espiñeira 1990 [1758], Havestadt 1990 [1777]), aunque haciendo énfasis en las actas de los parlamentos efectuados entre 1726 y 1803 en la frontera del Biobío, con el fin de reconocer las estrategias culturales mediante las cuales los pehuenches del siglo XVIII lograron mantener su particularidad como entidad social, pese

Las actas de los parlamentos fueron revisadas a partir de las transcripciones a digital realizadas por diversos investigadores y facilitadas al autor en el marco de su participación como tesista de Magister del proyecto FONDECYT $N^{\circ} 1120857$, entre los años 2012 y 2014. De todas maneras, si el lector desea acceder a esta información, el año 2015 vio la luz una valiosa edición de las transcripciones de las actas de los parlamentos hispano-indígenas coloniales, bajo la siguiente referencia: Los parlamentos hispanomapuches, 1593-1803: textos fundamentales. Zavala Cepeda, J. M. (Ed.). Temuco: Ediciones Universidad Católica de Temuco. Las citas textuales incorporadas en el presente artículo hacen referencia a esta última edición, para facilitar el cotejo a los lectores. 
a las transferencias culturales de las que participaron. A partir de estas fuentes se indaga particularmente sobre las características de la presencia pehuenche en la institución parlamentaria y qué objetivos perseguían sus líderes al pasar a participar de manera activa en el contexto fronterizo colonial (Toro 2015), para lo cual se pone énfasis en la perspectiva indígena y cómo se desenvolvieron en relación al resto del mundo colonial en general, incluyendo a los españoles y otros grupos indígenas.

\subsection{Las transferencias culturales $y$ distinciones étnicas en la frontera del Biobío}

Para poder argumentar la discusión efectuada más adelante, es necesario explicitar las definiciones de los conceptos a los que se ha hecho mención. En primer lugar, se entenderá por transferencia cultural a la relación entre dos sistemas autónomos y asimétricos, a través de la cual será posible distinguir y precisar los mecanismos que conducen al cambio, tanto en las sociedades de origen como en las receptoras. Además, esta conceptualización supone poner énfasis en la idea de "tomar" elementos desde otras culturas, subrayando el carácter de sujetos activos de las sociedades receptoras. Por ello, las transferencias culturales deben verse en términos tanto de las dinámicas de apropiación como de procesos adaptativos, lo que quiere decir que la conceptualización propuesta, se sustenta en la visión de las identidades culturales como realidades inestables y continuamente transformadas por medio de los contactos, conflictos e intercambios con otras culturas (Turgeon 1996: 14 y ss.). Otro aspecto importante para lo que se discute en el presente escrito es la necesidad de entender que las interacciones sociales se producen a escala de sujetos y grupos, generalmente materializadas por relaciones de parentesco, a través de las cuales se produce, en un espacio geográfico determinado, la circulación de bienes tanto materiales como simbólicos (Bello 2011: 42). Dichas interacciones se habrían producido en el contexto de organizaciones sociales del tipo de sistemas de linaje segmentarios (Sahlins 1972: 81 y ss.), en lo que se refiere a los grupos pehuenches analizados en el presente trabajo.

De manera complementaria a lo señalado hasta acá, se va a considerar a los grupos étnicos como formas de organización social que se definen a partir de categorías de adscripción e identificación que vienen dadas por los propios actores sociales que los conforman, aunque para su definición, también haya que considerar la visión que otros grupos sociales tienen sobre ellos. Es importante tener presente que los grupos étnicos solo persistirán como unidades sociales significativas si su comportamiento es marcadamente diferente al del resto de los grupos humanos que comparten con ellos un contexto fronterizo. En este sentido, se puede decir que cuando personas de culturas diferentes interactúan, uno podría esperar que dichas diferencias disminuyan, a partir del hecho que la mentada interacción requiere y genera una necesidad de congruencia de códigos y valores compartidos entre las sociedades involucradas (Barth 1969: 16). No obstante, pese a esta base común generada por el contacto interétnico, las diferencias pueden persistir más allá de la interdependencia y la incorporación de rasgos culturales ajenos (Boccara 2005; Abercrombie 1991), como se propone que ocurre en el caso pehuenche, quienes a pesar de haber estado inmersos en un doble proceso de transferencias culturales, aún sería factible considerarlos como un grupo étnico que se relaciona con otros, pero que mantiene su particularidad. 
En este sentido, un primer proceso de transferencias culturales del que participaron los pehuenches se relacionó con rasgos culturales del mundo mapuche tales como la lengua, las técnicas textiles y platería, la incorporación de algunas prácticas agrícolas (complementarias a la caza y el pastoreo) y las ceremonias religiosas, que fueron rápidamente incorporadas por las sociedades cordilleranas debido a la transformación de su estructura económica y motivada por el denominado "proceso de araucanización o mapuchización" (Mandrini y Ortelli 2002). Por una parte, dicha transformación estructural habría permitido una creciente interdependencia entre los grupos indígenas ubicados hacia ambas vertientes de la cordillera andina, generando a su vez una diferenciación interna de las comunidades indígenas orientales, expresada en procesos de jerarquización social, mediante el surgimiento de jefes o caciques. Todo esto permitido por la acumulación de elementos de origen foráneo por parte de estos personajes, los que eran altamente valorados en términos simbólicos (Mandrini y Ortelli 2002). Por otra parte, el proceso de araucanización de la cordillera y las pampas, que se dio por lo menos a partir del siglo XVII, hizo que muchos rasgos que se reconocen entre los grupos pehuenches del XVIII fueran similares a los de los mapuches del valle occidental, generado por el desplazamiento de estos últimos hacia el este, movimiento provocado principalmente con el fin de adquirir directamente el ganado cimarrón ubicado en las pampas orientales, para posteriormente comercializar dicho recurso en los puestos fronterizos del Biobío (Zavala Cepeda 2012; Valenzuela 2008; León Solís et al. 1997).

El otro proceso de transferencias culturales del cual participaron los pehuenches consistió en la generación de una alianza hispano-pehuenche, la cual cumpliría un doble propósito, visto desde la perspectiva europea: por un lado, serviría de barrera contra las malocas o malone ${ }^{2}$ de otros grupos indígenas pampeano-patagónicos $y$, por otro lado, mesuraría el efecto negativo que dichas incursiones estaban teniendo sobre el comercio de ganado y sal que provenía desde el oriente de la cordillera andina. En retribución a este doble rol, las autoridades hispanas ofrecieron a los pehuenches ayuda militar para hacer frente a las luchas interétnicas que sostenían con los mapuches Ilanistas y precordilleranos, y con las bandas orientales que disputaban con ellos los recursos que los sustentaban (Silva 2005). Este proceso que se dio con mayor intensidad desde mediados del siglo XVIII en adelante, es a lo que se refiere Zavala Cepeda (2008: 110 y ss.) cuando señala que las autoridades coloniales pasan a "mirar hacia oriente" en este momento del período colonial del mundo fronterizo. Lo anterior, por supuesto, generó una incorporación cada vez más marcada de la participación pehuenche tanto en los circuitos de intercambio fronterizo como en las instancias de negociación política, como se detallará en el siguiente apartado.

\subsection{Antecedentes históricos}

Los pehuenches o "gente del pehuén" podrían entrar en la categoría de puelches o "gente del este", tal como se mencionaba en mapudungun a cualquier agrupación social ubicada al este de los mapuches del valle occidental, de acuerdo a los primeros europeos que los describieron hacia el siglo XVI (p. ej. Bibar

Conflicto violento que movilizaba una fuerza colectiva, el cual tenía como objetivo principal apropiarse a la fuerza de la máxima cantidad de bienes (que eran comúnmente, mujeres y ganado) de un enemigo declarado (León Solís 1991). 
1966 [1558]: 136-137), quienes supuestamente seguían las etnodenominaciones de los propios "araucanos". De acuerdo a investigaciones previas, las parcialidades pehuenches ocuparon principalmente ambas vertientes de la cordillera andina desde las latitudes de los nevados de Chillán, por el norte y el volcán Villarrica, por el sur, coincidiendo con el ambiente donde se registra la araucaria (Araucaria araucana). En tanto que en el lado oriental, se asentaron en las zonas pre y cordilleranas de las actuales provincias de Mendoza y Neuquén (Villalobos 1989: 17 y ss.), excediendo el ámbito de distribución de la araucaria, especialmente en el siglo XVIII (Silva y Téllez 1993). Dichas regiones son las que constituyen el marco espacial del presente estudio (Imagen 1).

Imagen 1. Se muestran los pasos transcordilleranos ubicados en territorio pehuenche en el XVIII,

los principales asentamientos españoles e indígenas, la ubicación de las salinas orientales y el emplazamiento del parlamento de Lonquilmo de 1783-84 en ámbito pehuenche

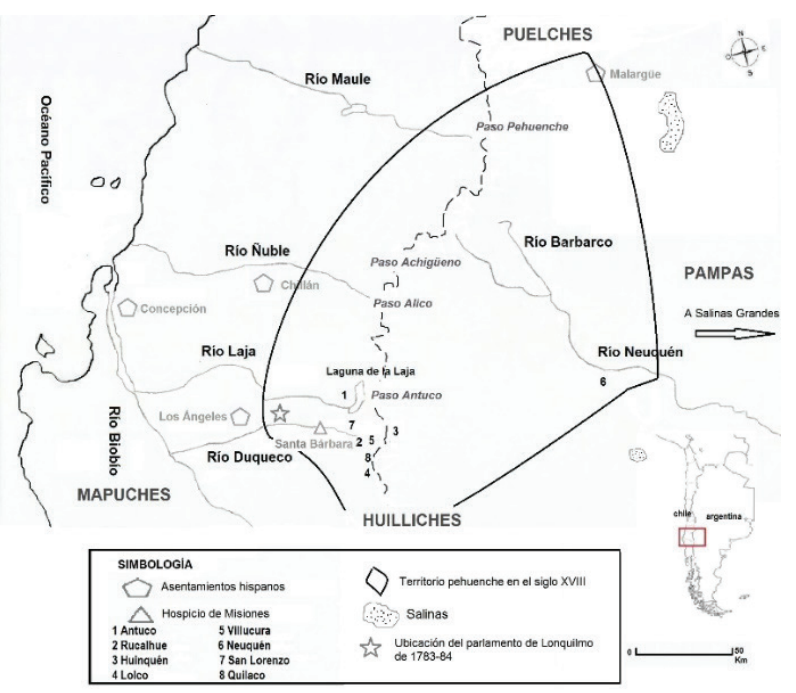

Fuente: elaboración propia.
Específicamente, hacia el siglo XVIII el contacto comercial hispano-indígena adquirió una alta importancia entre las dinámicas fronterizas de aquella época y fue consolidando un vasto circuito mercantil vinculado al movimiento de recursos entre la región pampeana y los valles occidentales, a través de los pasos andinos que tan bien conocían los pehuenches, lo que permitió una creciente interdependencia entre hispanocriollos e indígenas (Mandrini y Ortelli 2002). Estas actividades se materializaban en las plazas de Concepción, Chillán y Los Ángeles, además de los fuertes y las misiones fronterizas (Imagen 1), donde era común el tráfico de ganado, sal, ponchos, objetos de plata y alcohol (León Solís 2001; Varela et al. 1997; Villalobos 1995). Estos datos permiten afirmar que para el siglo XVIII la frontera del Biobío logró una notable integración interna y una clara articulación con el resto de la economía colonial, con resultados beneficiosos tanto para la región fronteriza, como para las zonas con las cuales se conectaba, como fueron algunos importantes mercados sudamericanos (p. ej. Buenos Aires, Uruguay, Lima, zona central de Chile) (Pinto Rodríguez 2003: 36 y ss.).

En cuanto a las modalidades de interacción social en la frontera hispano-araucana del último siglo colonial, éstas se caracterizaban por realizarse a través de juntas de indios ${ }^{3}$, parlas $^{4}$ y parlamentos, reflejando un equilibrio en la dinámica fronteriza, dejando atrás la tradición bélica característica del primer siglo y medio

Reuniones indígenas de carácter local, donde participaban caciques de distintas parcialidades (Zavala Cepeda 2008; Méndez 1982).

4 Reuniones hispano-indígenas de carácter pacíficas y locales, donde por lo general participaban funcionarios menores dentro del orden colonial y caciques de ciertas parcialidades (Zavala Cepeda 2008; Méndez 1982). 
de contacto (ca. 1550-1700). Debido a que una de las principales fuentes de información utilizada para esta investigación son las actas de los parlamentos, éstos se van a definir como instancias de mediación y negociación política que configuraron escenarios simbólicoculturales entre dos sociedades, la hispanocolonial y la indígena (Zavala Cepeda 2008; Méndez 1982). Algunos autores sitúan a los parlamentos como una institución impuesta por los españoles al contexto colonial americano y que se encontraba al servicio de los intereses europeos (p. ej. Méndez 1982; Villalobos 1982). Sin embargo, esta visión ha sido superada, en el sentido de dejar de ver la relación españolindígena fronteriza como un flujo unidireccional de dominación, en una suerte de hibridación cultural manifestada en estas instancias políticas. Así, los grupos indígenas coloniales habrían resistido permanentemente a la Corona española, tanto militar como políticamente, replicando la lógica del kojagtun ${ }^{5}$ y siguiendo protocolos indígenas, tales como las invitaciones, saludos, ubicación de asistentes, discursos, comensalías y despedidas (Zavala Cepeda 2008; Lázaro 2002), donde la perspectiva de las transferencias culturales es más adecuada a la realidad propuesta por este último punto de vista. Además, uno de los roles jugados por las instancias parlamentarias a lo largo del período colonial fue el de la adquisición y mantención del poder político de los jefes indígenas. Así, los parlamentos devienen en espacios en los cuales se refuerza y reafirma la estructura política indígena, tanto a nivel de los bienes distribuidos por los españoles como en los actos oratorios, los que seguían esquemas fijos en función a la jerarquía de los participantes (Boccara 2007:

Puede entenderse tanto como una instancia de resolución de conflictos en general, o como escenarios de discusión de asuntos políticos, propios de la tradición indígena (Zavala Cepeda 2008).
218; Lázaro 2002: 223 y ss.). En definitiva, sería en los parlamentos, y a través de la participación de los líderes pehuenches, donde podrían revelarse con mayor intensidad las transferencias culturales desde la perspectiva indígena, por lo que a continuación se releva el rol jugado por los representantes pehuenches en las reuniones políticas interétnicas del siglo XVIII.

\section{Liderazgos pehuenches en el siglo XVIII}

Como parte del análisis de las fuentes consultadas se ha generado un diagrama para esquematizar y sistematizar los datos de los distintos caciques pehuenches mencionados en las actas de los parlamentos del siglo XVIII, respecto a las siguientes variables: si tenían nombres cristianos o no y su lugar de proveniencia (Figura 1). Dichas variables se consideran fundamentales para justificar el tipo de relación con y validación ante el mundo colonial, junto con permitir dilucidar la posición geográfica de los grupos pehuenches más incorporados al mundo fronterizo del Biobío, permitiendo una aproximación hacia la explicación de cómo y por qué se dio un acercamiento hispano-pehuenche a medida que avanzaba el siglo XVIII.

\subsection{Evangelización de los pehuenches coloniales}

En las fuentes coloniales, al referirse a individuos de origen indígena, se establecía una distinción en cuanto a si los mismos podrían haber estado bautizados o no, aunque no de manera explícita, sino que a través de dos elementos: la anteposición de la denominación "don" justo antes del nombre de pila cristiano de algunos individuos. De esta manera, la mención de 
Figura 1. Esquema que muestra los nombres, según localidades de proveniencia y si tenían nombres cristianos o no, de los caciques pehuenches mencionados en las actas de los parlamentos hispano-indígenas del siglo XVIII indicadas en la parte inferior. En rojo se destacan los nombres de líderes indígenas que se registraron

tanto con nombre cristiano como indígena

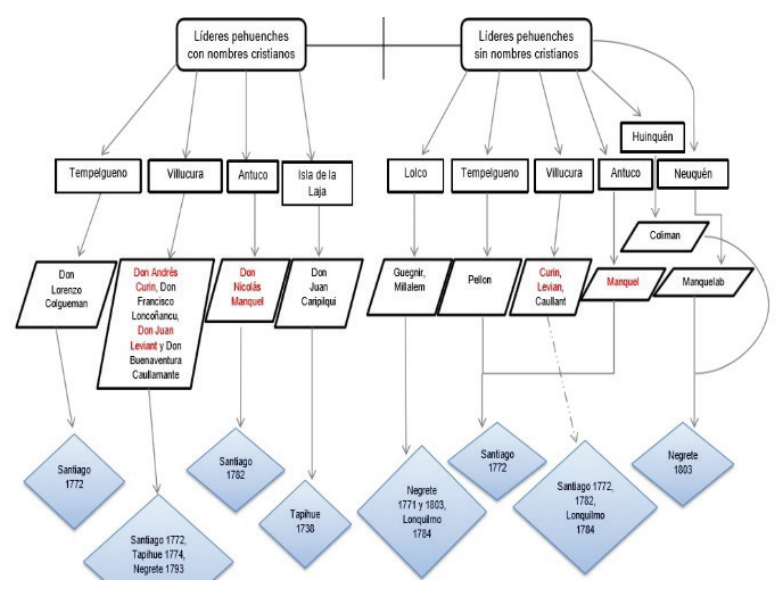

Fuente: elaboración propia, basado en la información contenida en Zavala Cepeda 2015; Bechis 2008; León Solís 2001.

personajes indígenas sin ninguno de estos elementos, debería estar indicando que ellos no habían sido bautizados aún. Es en base a este supuesto que se realizan las siguientes reflexiones.

De acuerdo a las actas de los parlamentos, se cuenta con datos sobre la proveniencia de caciques pehuenches con nombres cristianos para las localidades de Tempelgueno, Villucura, Isla de la Laja y Antuco, detectándose estos casos entre los años 1738 y 1793 (Figura 1). De esta manera, aparece mencionado don Juan Caripilqui de la Isla de la Laja, representante de los pehuenches según el acta del parlamento de Tapihue de 1738. Como caciques de Villucura están don Lorenzo Colgueman de Tempelgueno mencionado en los parlamentos de Santiago de 1772 y 1782, además de don Francisco Loncoñancu y don Juan Leviant que son anotados en Tapihue 1774, junto a don Buenaventura Caullamante, nombrado en el parlamento de Negrete de 1793. El otro caso es el de don Nicolás Manquel, quien aparece en las actas del parlamento de Santiago de 1782, como cacique de Antuco.

El tema de los bautizos a los indígenas, está directamente relacionado con las misiones. Para el ámbito cordillerano, estas acciones habían cobrado relevancia entre los gobiernos coloniales en dos etapas claramente discernibles: una a fines del siglo XVII, con la fundación de las misiones jesuitas de Cule y Lolco y mediante incursiones poco frecuentes de misioneros; y otra a mediados del siglo XVIII, mediante partidas de jesuitas y franciscanos en el territorio andino de la Araucanía. Estos procesos permitían el acercamiento español a los indígenas que habitaban estos espacios cordilleranos. A través de estas acciones evangelizadoras, se pretendía concretar dos proyectos coloniales vinculados entre sí: sedentarizar y reducir a los mencionados indígenas fronterizos en torno a los fuertes y centros misionales fundados por los españoles en la frontera del Biobío. No obstante, hasta mediados del siglo XVIII solamente se habían establecido las dos misiones mencionadas de Cule y Lolco (Zavala Cepeda 2008: 101) y ninguno de dichos proyectos coloniales tuvo el éxito esperado por las autoridades hispanas. Es por esta razón que en las actas de los parlamentos llevados a cabo durante el siglo XVIII y principios del XIX, se replican constantemente los artículos referidos a la solicitud efectuada por las autoridades 
hispanas hacia las comunidades indígenas fronterizas, para que éstas facilitaran el ingreso de los misioneros a sus asentamientos y se sometieran a la reducción territorial pretendida por los hispanocriollos. En este sentido, se propone que si bien los pehuenches del siglo XVIII facilitaron las incursiones misionales y se multiplicaron los bautizos entre sus líderes, esto no generó un cambio estructural entre dichas parcialidades, como habría sido modificar sus patrones de asentamiento y movilidad, debido fundamentalmente a los intereses indígenas de sacar provecho de su estatus de aliados de las autoridades hispanas. Se está de acuerdo con Boccara (2007: 217) cuando afirma que esta situación habría respondido a una necesidad política de alianza y generación de redes por parte de estas comunidades, más que a un real interés por acoger el nuevo credo.

Para dar cuenta de la estrategia puesta en práctica por los pehuenches, se acude, en primer lugar, a algunos pasajes extraídos del diario del viaje entre los pehuenches realizado por el misionero franciscano -y posterior Obispo de Concepción- Pedro Ángel de Espiñeira en 1758. En una primera instancia, el sacerdote pasa por el asentamiento estival del cacique Catiqueu, quien había solicitado su visita en el último parlamento ${ }^{6}$ y donde había una población

No se tiene certeza a cuál parlamento se refiere Espiñeira, ya que el último encuentro general se había producido en Tapihue en 1746, donde no se registra ninguna referencia a esta petición. Aunque, por los antecedentes que entrega respecto a que el referido parlamento fue convocado por el gobernador Amat y Junient, probablemente está hablando del parlamento de Salto del Laja en 1756 (puesto que los parlamentos generales que dirige dicho gobernador, tuvieron lugar en Concepción y Santiago, recién uno y dos años después del viaje de Espiñeira, respectivamente), donde los pehuenches aceptaron la presencia de misioneros en sus territorios, lo que se intentó concretar por medio de la fundación de la plaza de Santa Bárbara en 1757, alrededor de una hospedería de misioneros franciscanos, además de dos casas de conversión, en Rucalhue y Lolco (Orellana 1992). indígena numerosa. Se dice que este lugar quedaba hacia el noreste de la Laguna de la Laja, "donde corren ya las aguas al este" (Espiñeira 1990 [1758]: 12). Ante la petición de bautizo que le hicieron los indígenas de la toldería de Catiqueu, el franciscano les respondió que le habían contado que,

Ellos querían sólo a sus hijos por la cháquira, agujas, añil, tabaco y otros agasajos que los que bautizaban les dejaban, sin más estimación ni juicio de una cosa tan grande como es el bautismo (...) que por no saber ni entender esto vivían después del bautismo como antes, con muchas mujeres cada uno, embriagándose y matándose con el vino que a sus tierras traen los huincas o españoles (Espiñeira 1990 [1758]: 15)

Resulta interesante contrastar esta información con la que anota el propio Espiñeira en una conversación sostenida con el cacique pehuenche Painequeu. Este personaje había asistido al parlamento del gobernador Amat y Junient (ver nota al pie número 7) y tenía su toldería "que es de mucha gente" emplazada en un sector intercordillerano a orillas del río Laja, lugar intransitable en invierno por la nieve. En una conversación sostenida entre el misionero y Painequeu este último le reclamaba que no servía que solamente una vez al año entrasen los misioneros a bautizar en sus territorios, puesto que una vez consumada esta acción no se veían mayores cambios:

Que de que sirve entre a echar el agua el padre a sus gueñes una vez al año, si luego se va y los deja como estaban? Que los que decían que ellos se cristianizaban por el interés eran los que poco saben. Que en todas partes había buenos y malos y ellos por eso habían pedido al señor presidente un padre de buen corazón, que estando acá les enseñase y sería otra cosa (Espiñeira 1990 [1758]: 18-19).

En segundo lugar, el jesuita Bernardo Havestadt en 1777, 20 años después de lo señalado por Espiñeira, destaca el hecho que los propios 
indígenas grafican lo ocasional de las visitas misioneras y lo desconocido que se estaba haciendo la presencia de evangelizadores entre los pehuenches. Así, el propio misionero explica por qué la presencia de sacerdotes entre los pehuenches no era más permanente ni constante:

\begin{abstract}
Como les respondiese que ahora visitaba este lugar y pronto un otros y que ahora había acudido por el único motivo de encontrarlos a todos juntos y congregados, pues visitarlos a todos era imposible por la dificultad de los caminos y las distancias (Havestadt 1990 [1777]: 55, énfasis agregados).
\end{abstract}

De lo anterior se puede seguir que la política jesuita de evangelización de los pehuenches se encontrócondificultadesdeaccesoalastolderías pehuenches, las que además se distribuían espacialmente disgregadas. Aparentemente, se aprovechaba alguna festividad indígena que congregara mayor cantidad de individuos para realizar las incursiones misioneras, que en este caso era un cahuín ${ }^{7}$ efectuado por los pehuenches de Punmahuida.

Complementando la información sobre la relación de los pehuenches y las misiones que incursionaban en su territorio y que dan cuenta de los procesos de transformación que estaban produciéndose entre estos indígenas, se consideraron las trayectorias individuales de tres líderes indígenas consignados en las actas de los parlamentos del siglo XVIII, quienes pasaron de mencionarse como no bautizados a recibir la designación correspondiente a individuos que habían sido bautizados. Son los casos de los caciques nombrados como Curin, Levian y Manquel, todos quienes se hicieron presentes en el parlamento de Santiago de 1772 (Figura 1).

Reunión ritual, asimilable a una fiesta indígena (Zavala Cepeda 2008).
Sin embargo, en el parlamento general posterior, es decir, en Tapihue 1774, es posible apreciar que dos de los mencionados caciques se encontrarían bautizados para este encuentro, por llevar antepuesta la denominación "don" y el nombre de pila cristiano: se trataba de don Andrés Curin y de don Juan Leviant. Posteriormente, en el parlamento de Santiago de 1782, Manquel aparece nombrado como don Nicolás Manquel. Fruto de los vínculos que comenzaban a darse entre los pehuenches y los grupos hispanocriollos, en especial desde mediados del siglo XVIII, este proceso desde un probable estado de no bautizado a uno de haber adquirido el nombre cristiano, aparenta seguir la misma lógica en cuanto a las estrategias tanto hispanas como pehuenches para relacionarse entre sí. Ahora bien, recordando el supuesto interés creado de los indígenas cordilleranos por recibir el bautizo cristiano, era predecible que pese al nuevo estatus de ciertos representantes indígenas dichos grupos continuaran con su modo de vida caracterizados por la poligamia, rituales tradicionales y asentamientos dispersos en tolderías, en especial si las acciones misionales entre ellos no fueron realizadas de manera sistemática por ninguna de las órdenes religiosas que lo intentaron entre fines del siglo XVII y mediados del XVIII.

A partir de los datos expuestos en este apartado es posible apreciar que existían diversas versiones sobre la recepción del mundo pehuenche a los intentos evangelizadores por parte de la sociedad hispana. Por un lado, se solicitaba la presencia de misioneros en sus tierras con el fin de obtener beneficios políticos y económicos. Por otro lado, las dificultades con las que se topaban los sacerdotes que realizaban incursiones hacia el ámbito fronterizo cordillerano jugaron en contra de una práctica 
habitual de bautizo entre los pehuenches. Estas versiones no son contradictorias entre sí, puesto que son coherentes con el contexto de transformación sociocultural que estaban viviendo los pehuenches en el siglo XVIII y formaban parte de las estrategias desplegadas por dichos grupos en su intento por posicionarse de manera protagónica en la dinámica fronteriza del Biobío.

\subsection{La organización sociopolítica pehuenche a partir de conceptos hispanos: "reducción/ parcialidad", "cacique gobernador/cacique principal"}

El concepto "reducción" era utilizado en las fuentes coloniales como sinónimo del término mapuche ayllarewe ${ }^{8}$, palabra cuya etimología se desglosa en "nueve" (aylla) "parcialidades" (rewes). Como se ve, dentro de lo que era la denominación de reducción, también se incluye la designación de "parcialidad", donde destacaba la presencia de un jefe indígena o cacique. De esta manera, la reducción indígena o ayllarewe era representada por un "cacique principal o gobernador", tal como eran denominados por los españoles. Es así, que para los fines estratégicos de las autoridades coloniales, vinculados a la guerra y las misiones, los ayllarewe mapuches se entendieron como reducciones, retomando incluso los nombres de aquéllos (p.ej. Arauco, Boroa, Tucapel). Una aclaración necesaria en este punto, es que

Pese a que territorialmente era una unidad bien definida, era variable tanto en su extensión geográfica como en el número de rewes que lo conforman (cinco, siete, nueve y diez) entre los siglos XVI y XIX, reuniendo a un número de caciques proporcional bajo un cacique gobernador o apoulmen. Además, se conformaban como estructuras políticas donde se tomaban decisiones sobre varios temas que afectaban a las agrupaciones que los conformaban, no restringiéndose solamente a instancias de confrontación bélica (Zavala Cepeda 2008, Goicovich 2004). para el caso de la frontera hispano-indígena del Biobío el término reducción no fue resultado de una política concentracionista colonial, así como tampoco indicaba necesariamente subordinación al control político que trataron de imponer las autoridades coloniales sobre los grupos indígenas, a través de los misioneros y capitanes de amigos ${ }^{9}$ (Zavala Cepeda 2008). Esto no significó, sin embargo, que los gobiernos coloniales no hayan intentado aplicar dichas políticas concentracionistas y de subordinación sobre la población indígena fronteriza, como se vio en el apartado anterior.

Retomando el análisis de las conceptualizaciones hispanas aplicadas a la realidad indígena, el término "cacique gobernador" era entendido como sinónimo de "cacique principal" y ambos hacían referencia al jefe de una reducción indígena o ayllarewe. Vinculado a estos personajes, existía una política vigente al menos desde principios del siglo XVIII, tendiente a supeditar a estas autoridades indígenas bajo el poder colonial, de manera de alcanzar la mayor extensión de dicho poder entre la población mapuche, bajo el supuesto que si los jefes locales eran reconocidos por sus representados, éstos a su vez también seguirían lo que indicaran las autoridades coloniales (Zavala Cepeda 2008: 267).

A continuación se tratará de aclarar cómo se aplicaron los términos de "reducción-parcialidad" y "caciques principales-caciques gobernadores"

Personajes hispanocriollos o mestizos que hacían de nexo y traductores entre las autoridades coloniales y los grupos indígenas aliados de los españoles, viviendo entre las parcialidades que tenían a su cargo y muchas veces, adquiriendo costumbres propiamente indígenas (p. ej. poligamia). Estaban dentro de los mejores conocedores del mundo mapuche y recorrían la Araucanía y Valdivia junto a las autoridades coloniales y republicanas, participando prácticamente de cada reunión, tratado o Parlamento que tomó lugar en el ámbito fronterizo entre los siglos XVII y XIX (Vergara 2005; Zavala Cepeda 2008). 
a la realidad pehuenche del siglo XVIII, en el entendido que los mismos hacen referencia a organizaciones sociopolíticas y territoriales propias del mundo indígena. En primer lugar, el término "reducción" se vincularía a un orden más bien relacionado con los grupos mapuches de los valles occidentales, aplicado de forma reiterada a las agrupaciones indígenas que conformaban los vutanmapu ${ }^{10}$ de la costa, los llanos y cordillera, sobre todo en los primeros siglos de la Colonia (XVI-XVII). La denominación de reducción aplicada al vutanmapu pehuenche es más tardía, observada específicamente en las últimas cuatro décadas del siglo XVIII. Es así que en las actas de los parlamentos revisados se utiliza el concepto de reducción vinculado al ámbito pehuenche, específicamente para las localidades de San Lorenzo, Antuco, Lolco, Rucalhue, Quilaco, Santa Bárbara y Villucura (Imagen 1). Que en los parlamentos se haya denominado bajo este término a localidades donde se asentaban grupos pehuenches puede significar que los españoles estaban incluyendo a este vutanmapu como parte de los procesos sociales de la Araucanía, intentando asimilar a los pehuenches, que eran parcialidades relativamente desconocidas hasta inicios del siglo XVIII, con la realidad observada para los grupos mapuches conocidos previamente. Por lo tanto, serían las autoridades coloniales quienes estarían adscribiendo a los pehuenches a la realidad de los grupos mapuches de los valles occidentales,

10 Grandes alianzas territoriales longitudinales del territorio mapuche, bajo las cuales se agrupaban varios ayllarewes. Se dividían en 4 sectores geográficos, mencionados de oeste a este: Lafquen-vutanmapu, correspondía a las planicies costeras entre el Océano Pacífico y la cordillera de la Costa o de Nahuelbuta; Lelfün-vutanmapu, que designaba el valle o llano de la Araucanía que se sitúa entre la cordillera de Nahuelbuta y la precordillera andina; Inapire-vutanmapu, era la forma de designar al territorio correspondiente a la precordillera de la Araucanía; y el Pirevutanmapu, que incluía a los valles interandinos, en sus vertientes occidental y oriental (Zavala Cepeda 2008). entregando una imagen homogeneizada sobre el comportamiento de la sociedad indígena de la Araucanía y los valles interandinos, lo cual hace necesario y pertinente cuestionarse sobre si dicha imagen reflejaba realmente lo que ocurría hacia el oriente de los valles occidentales, tal como se analiza más adelante en este trabajo.

En segundo término, el concepto "parcialidad" se encontró asociado en referencia a dos variables: en ocasiones se usó para distinguir la organización social de grupos pehuenches orientales y sus acompañantes pampas, en especial cuando dichas agrupaciones eran previamente desconocidas para los españoles participantes de los parlamentos, tal como se aprecia en las siguientes citas extraídas de las actas de Lonquilmo en 1784:

\begin{abstract}
Fueron succesivamente, llegando los Yndios, siendo los primeros los pehuenches que trayendo en su comitiva nuevas parcialidades desde la parte oriental del Rio Neuquen, y de los paises interiores inmediatos a las Panpas de Buenos Ayres, que hasta aora no se conosian, se presentaron con su acostumbrada arrogancia partiendo con violencia, y manejando con la mayor destreza sus caballos al mismo tiempo, que con otras demostraciones de gozo publicaban el Viva el Rey (...) Preparado todo lo necesario para su subsistencia en los dias precisos de asistencia en este Parage, se anticiparon los Peguenches en numero considerable saliendo de sus Cordilleras aun antes del dia prefixado con varias Parcialidades de Yndios Pampas (Zavala Cepeda 2015: 351, 364, énfasis agregados).
\end{abstract}

En base a estos datos, se puede especular que en las fuentes consultadas se hacía referencia a "parcialidades pehuenches" cuando los grupos aludidos no tenían contacto permanente con los españoles o no eran conocidos por ellos previamente, suponiendo una organización sociopolítica distinta a las alianzas indígenas de mayor magnitud que incluían varias reducciones o ayllarewes. Parece ser que los europeos asociaron a estos 
grupos, que se presentaban por primera vez a los parlamentos, con organizaciones socioterritoriales consistentes en tolderías cercanas entre sí y bajo el mando de un jefe local, si se siguen las anotaciones de algunos misioneros que incursionaron esporádicamente en territorio oriental (p. ej. Havestadt 1990 [1777]; Espiñeira 1990 [1758]). Por otra parte, tal como se deduce a partir de la tabla esquematizada al final del acta del parlamento de Negrete de 1803, el término "parcialidad" también hacía referencia a una variante geográfica, específicamente para diferenciar las localidades desde donde provenían los caciques y acompañantes de cada uno de los vutanmapu participantes del encuentro (en Zavala Cepeda 2015: 424-429, se reproduce dicha tabla. Ver Tabla 2). En definitiva, se sostiene que durante el período colonial los conceptos de reducción y parcialidad que se utilizaron en las actas de los parlamentos del siglo XVIII hacían referencia principalmente a la forma de organización sociopolítica presentada por los distintos "tipos" de pehuenches incorporados o que se estaban adentrando en el mundo fronterizo mediante su participación en dichos encuentros interétnicos.

Eso sí, tanto las reducciones como las parcialidades eran presididas por un "cacique gobernador" o "cacique principal", indistintamente, términos aplicados a las autoridades pehuenches de manera explícita al menos desde el parlamento de Negrete en 1771 (Tabla 1). Un ejemplo de dicha denominación se puede leer en el acta de Tapihue en 1774: "se le precentaron los Casiques Governadores Don Juan Leviant de el Butalmapu de Peguenches (...) y otros Casiques principales" (Zavala Cepeda 2015: 323, énfasis agregados). Lo mismo se encuentra en un pasaje del acta de Negrete en 1793: "el Muy llustre señor
Tabla 1. Comparación entre los líderes pehuenches mencionados en las actas de los parlamentos del siglo XVIII, respecto a su denominación, origen y si provenían de una reducción o no

\begin{tabular}{|c|c|c|}
\hline $\begin{array}{l}\text { Listado de } \\
\text { pehuenches/ } \\
\text { Parlamento(s) }\end{array}$ & $\begin{array}{l}\text { Denominación } \\
\text { a los } \\
\text { representantes } \\
\text { pehuenches } \\
\end{array}$ & $\begin{array}{l}\text { Proveniencia/ } \\
\text { Referencia a } \\
\text { reducciones }\end{array}$ \\
\hline $\begin{array}{c}\text { Don Juan Caripilqui/ } \\
\text { Tapihue } 1738\end{array}$ & $\begin{array}{c}\text { Cacique } \\
\text { pehuenche }\end{array}$ & $\begin{array}{l}\text { Isla de la Laja/Sin } \\
\text { referencia }\end{array}$ \\
\hline $\begin{array}{c}\text { Guegnir o Guener/ } \\
\text { Negrete 1771; } \\
\text { Lonquilmo 1783-84/ } \\
\text { Negrete } 1803 \\
\end{array}$ & $\begin{array}{l}\text { Caciques } \\
\text { principales }\end{array}$ & $\begin{array}{l}\text { Lolco/Se hace } \\
\text { referencia a las } \\
\text { reducciones de } \\
\text { pehuenches en general }\end{array}$ \\
\hline $\begin{array}{c}\text { Don Lorenzo } \\
\text { Colgueman y su hijo } \\
\text { Pellon/ Santiago } 1772 \\
\text { y } 1782\end{array}$ & \multirow{2}{*}{$\begin{array}{l}\text { Caciques } \\
\text { principales y } \\
\text { capitanes }\end{array}$} & $\begin{array}{l}\text { Tempelgueno/Se } \\
\text { menciona como } \\
\text { reducción }\end{array}$ \\
\hline $\begin{array}{c}\text { Curin/ Santiago } 1772 \\
\text { y } 1782 \\
\end{array}$ & & $\begin{array}{c}\text { Villucura/ Se menciona } \\
\text { como reducción }\end{array}$ \\
\hline $\begin{array}{c}\text { Don Francisco } \\
\text { Colgueman/ Tapihue } \\
1774\end{array}$ & \multirow{4}{*}{$\begin{array}{l}\text { Caciques } \\
\text { gobernadores } \\
\text { y Caciques } \\
\text { principales }\end{array}$} & $\begin{array}{c}\text { No se indica } \\
\text { (aparentemente } \\
\text { emparentado con } \\
\text { Lorenzo Colgueman, } \\
\text { por lo que podría ser } \\
\text { de Tempelgueno) }\end{array}$ \\
\hline $\begin{array}{c}\text { Don Francisco } \\
\text { Loncoñancu/ Tapihue } \\
1774\end{array}$ & & $\begin{array}{c}\text { Posiblemente } \\
\text { de Villucura, por } \\
\text { parentesco con Andrés } \\
\text { Curin/Se menciona } \\
\text { como reducción }\end{array}$ \\
\hline $\begin{array}{c}\text { Don Santiago } \\
\text { Pichiumanque y don } \\
\text { Agustín Lepiñan/ } \\
\text { Tapihue } 1774\end{array}$ & & No se indica \\
\hline $\begin{array}{c}\text { Don Juan Leviant/ } \\
\text { Tapihue } 1774\end{array}$ & & $\begin{array}{l}\text { Villucura/Se menciona } \\
\text { como reducción }\end{array}$ \\
\hline $\begin{array}{c}\text { Don Nicolás Manquel/ } \\
\text { Santiago } 1782\end{array}$ & $\begin{array}{l}\text { Caciques } \\
\text { principales }\end{array}$ & $\begin{array}{c}\text { Antuco/Se menciona } \\
\text { como reducción }\end{array}$ \\
\hline $\begin{array}{c}\text { Caullant/Lonquilmo } \\
\text { 1783-84 } \\
\end{array}$ & No se indica & $\begin{array}{c}\text { Villucura/Se menciona } \\
\text { como reducción }\end{array}$ \\
\hline $\begin{array}{c}\text { Don Buenaventura } \\
\text { Caullamante/ Negrete } \\
1793 \\
\end{array}$ & $\begin{array}{l}\text { Cacique } \\
\text { gobernador }\end{array}$ & $\begin{array}{c}\text { Villucura/Se menciona } \\
\text { como reducción }\end{array}$ \\
\hline $\begin{array}{c}\text { Coliman o Coigueman/ } \\
\text { Negrete } 1803\end{array}$ & $\begin{array}{c}\text { Cacique } \\
\text { gobernador }\end{array}$ & $\begin{array}{l}\text { Huinquien o Huinquén } \\
\text { (sector oriental)/No se } \\
\text { indica }\end{array}$ \\
\hline $\begin{array}{c}\text { Manquelab/ Negrete } \\
1803 \\
\end{array}$ & $\begin{array}{c}\text { Cacique } \\
\text { gobernador }\end{array}$ & $\begin{array}{c}\text { Neuquén (sector } \\
\text { oriental)/No se indica }\end{array}$ \\
\hline Millalem/ Negrete 1803 & $\begin{array}{c}\text { Cacique } \\
\text { gobernador }\end{array}$ & Lolco/No se indica \\
\hline
\end{tabular}

Fuente: elaboración propia, basada en la información contenida en Zavala Cepeda 2015; Bechis 2008; León Solís 2001. 
Tabla 2. Resumen de caciques pehuenches, parcialidades y número de participantes de dicho vutanmapu que participaron del Parlamento de Negrete de 1803

\begin{tabular}{|c|c|c|}
\hline $\begin{array}{c}\text { Caciques } \\
\text { pehuenches }\end{array}$ & $\begin{array}{c}\text { Parcialidades de } \\
\text { origen }\end{array}$ & $\begin{array}{c}\text { Número de } \\
\text { participantes de } \\
\text { las parcialidades } \\
\text { pehuenches }\end{array}$ \\
\hline $\begin{array}{l}\text { Manquelab, } \\
\text { Chicalab }\end{array}$ & Neuquén & 55 \\
\hline $\begin{array}{l}\text { Millalem (más tres } \\
\text { caciques que no } \\
\text { se especifican) }\end{array}$ & Lolco & 41 \\
\hline Coliman & Huinquien & 18 \\
\hline Manquemilla & Callaqui & 19 \\
\hline Liupay & Quilaco & 23 \\
\hline $\begin{array}{c}\text { Calbuqueu (más } \\
\text { cuatro caciques } \\
\text { que no se } \\
\text { especifican) } \\
\end{array}$ & Daquegue & 65 \\
\hline $\begin{array}{l}\text { Huenteman, } \\
\text { Purayñanco }\end{array}$ & Villucura & 55 \\
\hline $\begin{array}{l}\text { Huentellau (más } \\
\text { otro cacique que } \\
\text { no se especifica) }\end{array}$ & Trapatrapa & 41 \\
\hline Apeleb & Cura & 27 \\
\hline Lincopan & Palihue & 22 \\
\hline Huaychapan & Huambali & 28 \\
\hline Guinalab & Dugmu & 22 \\
\hline $\begin{array}{c}\text { Total participantes } \\
\text { pehuenches }\end{array}$ & \multicolumn{2}{|c|}{416} \\
\hline
\end{tabular}

Fuente: elaboración propia, basado en información presentada en Zavala Cepeda 2015: 429.
Precidente Don Ambrocio Higgins Vallenar, hizo llamar a su presencia al cazique Governador de Pehuenchez Don Buenaventura Caullamante, a Calbuqueu, Ynaiman y otros principales de esta misma Nacion" (Zavala Cepeda 2015: 394, énfasis agregados).

A partir de lo señalado en este apartado, se percibe que es posible diferenciar a los grupos pehuenches de los mapuches vallunos, pese al intento por homologarlos con la realidad indígena mejor conocida por los españoles. Esto se observa en las fuentes analizadas cuando se mencionan agrupaciones provenientes del Puel Mapu ${ }^{11}$ que no participaban regularmente de las instancias de negociación interétnica, asociándolas con organizaciones sociopolíticas diferentes, denominadas bajo el término "parcialidades" y que se vinculan generalmente a alusiones tales como "pehuenches del sur" y "pehuenches orientales"12. En tanto que los "pehuenches fronterizos" se asociaban al concepto de "reducción", en especial a partir del parlamento de Negrete en 1771, ya que eran mejor conocidos por los españoles y podían asimilarse al tipo de organización sociopolítica conocido como ayllarewe en el mundo mapuche. Es así que los pehuenches

11 "Territorio del este". Se refiere al espacio que abarca desde la vertiente oriental de la cordillera de los Andes hasta el Océano Atlántico (León Solís 2001).

12 En ciertos pasajes de las actas de los parlamentos consultados (Lonquilmo 1784, Negrete 1793, Negrete 1803 en Zavala Cepeda 2015) se alude a una subdivisión del mundo pehuenche en 2 grandes agrupaciones que no formaban parte de la frontera del Biobío (donde se incluían a los "pehuenches fronterizos", considerados aliados de los españoles):

"Pehuenches orientales": corresponden a grupos del este del río Neuquén y la pampa, y se los describe como conflictivos, ya que provocaban continuas malocas sobre las haciendas hispanocriollas y con otras comunidades indígenas.

"Pehuenches del sur": se incluían dentro de una agrupación de indígenas (junto a huilliches y pampas) que mantenían correrías en las haciendas hispanocriollas fronterizas. 
fronterizos, al estar más cercanos al área del Biobío, se habrían asimilado a los modos de vida araucanos (lato sensu), es decir, con una mayor participación dentro de los procesos de transferencias culturales propias de un ámbito fronterizo, impulsada por el proceso de mapuchización explicitado. Por el contrario, los pehuenches orientales y del sur, al tener menos contacto con los mapuches occidentales y los propios hispanocriollos, aún estaban insertos en dinámicas sociales pampeanas, lo que estaba comenzando a cambiar a partir de las últimas décadas del siglo XVIII, particularmente desde el parlamento de Negrete de 1771, con una mayor incorporación de parte de dichas agrupaciones al mundo fronterizo, probablemente como parte de estrategias sociopolíticas puestas en práctica por los líderes de aquellos grupos. Dichos cambios pueden resumirse en la siguiente propuesta de cronología de las relaciones interétnicas que sostuvieron los pehuenches, en particular con los españoles.

Figura 2. Esquema que muestra los cinco momentos de los parlamentos hispano-indígenas donde destacan los grupos pehuenches, las acciones y efectos en cada uno de dichos momentos

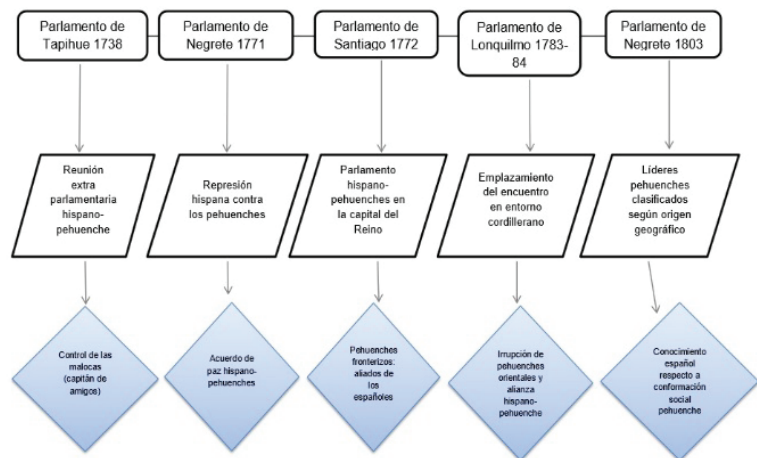

Fuente: elaboración propia.
3. Propuesta de periodificación para las relaciones hispano-pehuenches del siglo XVIII

Para sistematizar la información recabada, se generó un esquema que sintetiza los cinco momentos que se destacan del análisis de las fuentes del siglo XVIII (Figura 2), a través de los cuales se puede apreciar el devenir de la relación hispano-pehuenche y cómo estos últimos fueron adquiriendo protagonismo en las dinámicas sociopolíticas fronterizas del Biobío a medida que avanzaba el período Colonial. A continuación se describen dichos momentos.

\subsection{Primer momento: malocas pehuenches sobre haciendas hispanocriollas (1726-1764)}

De los siete primeros parlamentos revisados para el siglo XVIII, solamente en Tapihue 1738 existe referencia directa a representantes pehuenches. No obstante, aparentemente éstos no habían participado de dicho parlamento, ya que se los menciona solamente al final del acta y como parte de una parla hispano-pehuenche en el fuerte de Purén, la que tuvo por finalidad solicitar que los jefes pehuenches don Juan Caripilqui y don Diego Copillan aceptasen la presencia de un capitán de amigos entre ellos para poder controlar las constantes malocas que estas agrupaciones indígenas perpetraban contra los asentamientos hispanocriollos fronterizos. La no mención a los pehuenches en el resto de las actas de este período se podría atribuir, alternativamente, a la ausencia de representantes de dichas parcialidades o a una participación marginal en los encuentros parlamentarios que los dejó fuera del registro en las fuentes hispanas. En definitiva, este primer momento podría calificarse como uno de relaciones hispano-pehuenche beligerantes y de poco conocimiento mutuo. 


\subsection{Segundo momento: acuerdos de paz hispano-pehuenches (1771)}

En cuanto a la relevancia de la presencia pehuenche en las instancias de parlamentos, se puede observar una participación mucho más activa y protagónica recién desde la década de 1770 , específicamente a partir de Negrete 1771. Además de tener un rol destacado en los acuerdos alcanzados en los encuentros parlamentarios, también se muestran como un grupo heterogéneo y poco conocido por las propias autoridades coloniales, lo que devela lo tardío de su incorporación a las dinámicas fronterizas del Biobío. Esto podría encontrar una explicación en lo señalado tanto por León Solís (1991: 80 y ss. para una discusión de este tema) como por Boccara (2007: 322), quienes sostienen que el ganado obtenido desde las haciendas hispanocriollas en las malocas fronterizas del siglo XVIII era mayoritariamente intercambiado y explotado al interior de las propias comunidades indígenas. Esto, con el fin de ser utilizado en las parlas previas y posteriores a los parlamentos, como alimento y materia prima para la construcción de toldos, coincidiendo con el aumento significativo de los encuentros parlamentarios y la actividad maloquera hacia la segunda mitad del siglo XVIII. A partir de lo anterior se postula que tal como las autoridades coloniales comenzaron a mirar hacia oriente a partir de mediados del siglo XVIII (Zavala Cepeda 2008: 110 y ss.), es posible suponer que fueron los propios pehuenches quienes lucharon por posicionarse de manera estratégica respecto a su estatus político, ya que de lo contrario serían subsumidos, ya sea como mano de obra para los asentamientos hispanocriollos o por el avance mapuche sobre el territorio cordillerano andino y las pampas trasandinas.
3.3. Tercer momento: los pehuenches fronterizos como aliados de los españoles (1772-1782)

A partir del parlamento de Santiago en 1772 se refleja de mejor manera la intención de los pehuenches fronterizos por aliarse con las autoridades coloniales y adquirir un mayor protagonismo en las diferentes situaciones sociales y políticas que se estaban desarrollando en el área fronteriza del Biobío. El hecho de acudir con sus principales autoridades a la capital del Reino reflejaba estas estrategias, las que se van a ir desplegando de manera cada vez más marcada a partir de este parlamento y tendrán su expresión en los siguientes encuentros diplomáticos realizados en el último tercio del siglo XVIII. En ese sentido, es posible afirmar que las relaciones interétnicas hispanoindígenas hacia fines del período colonial se sustentaron en gran parte en lo que sucedía hacia el Puel Mapu, puesto que por ahí pasaban muchos de los bienes comercializables de los virreinatos del Perú y La Plata, al ser una zona por donde circulaban objetos e ideas. El tema de las vías de circulación y acceso a recursos es complejo, puesto que parte del poder que acumulaban los caciques cordilleranos y trasandinos estaba dado, justamente, por el control que ejercían sobre los pasos y rutas. Así, los líderes indígenas surgidos durante la segunda mitad del siglo XVIII también adquirieron ascendencia sobre sus respectivas parcialidades mediante modificaciones en la distribución territorial, redes de alianzas y contactos con el mundo hispanocriollo (Villar y Jiménez 2000). 


\subsection{Cuarto momento: parlamento general en territorio pehuenche (1784-1793)}

La década de 1780 es testigo de la posición preeminente de las parcialidades pehuenches dentro del mundo indígena fronterizo, y muchos de los acuerdos y regulaciones se establecen en base a lo que dichas parcialidades solicitan a las autoridades coloniales. El momento más representativo en que se puede apreciar dicho protagonismo, es el parlamento de Lonquilmo de 1783-84 efectuado en territorios que solían ser frecuentados por grupos pehuenches (Imagen 1). Un ejemplo que ilustra la relación hispano-pehuenche durante este período, es la alianza entre Ambrosio O'Higgins, en ese entonces Comandante General de la Frontera, y el cacique pehuenche Ancan. A través de esta clase de acuerdos, los pehuenches lograron que las autoridades coloniales obligaran a que se les dispensara un buen trato a quienes interactuaban con ellos cuando bajaban a comerciar desde la cordillera a través de los boquetes andinos, tal como se lee en el artículo 5 del acta del mencionado parlamento de Lonquilmo:

Que para inducir a los yndios vagantes de las Cordilleras al trato y comunicacion amigable con el español se le permite tener comercio franco de todos los frutos que produsen sus tierras: que podran libremente introducirlos por los Voquetes de Villacura y Antuco que caen sobre esta Ysla de la Laxa por los de Alico y Renegado en la Provincia de Chillan, y por los caminos del Cerro Colorado y Curicò en lo que hase el Partido de Maule, a cuio efecto se previene a los Corregidores, Justicias y Comandantes de Milicias de estos distritos que estan presentes, y se intimarà a los ausentes a nombre del Señor Capitan General que coadyuben eficazmente a esta disposición, recomendandoles y ordenandoles fomenten y auxilien a los Pehuenches y demas naciones en su introducion, venta y cobro de los ramos de comercio reciprocamente ventajoso donado que el interes resultante les sirva de estimulo a preferir este horroroso y comodo trajin al de incursiones infames sobre las Pampas tan contrario y perjudicial al [j]iro considerable que hacen los españoles con notable y manifiesto riesgo de vidas y haciendas (Zavala Cepeda 2015: 355, énfasis agregados).

De la cita precedente también se sigue que para los líderes hispanocriollos la alianza con los pehuenches cumplía una función política y estratégica al buscar la seguridad del Reino, puesto que al auxiliar a la gente del piñón en sus luchas contra los huilliches se impedía el ingreso de estos grupos rebeldes que provocarían robos y caos en las haciendas fronterizas. La ayuda material hacia los pehuenches era necesaria por tratarse de parcialidades poco numerosas (Zavala Cepeda 2007).

\subsection{Quinto momento: consolidación de la alianza hispano-pehuenche y mejor conocimiento español sobre la organización social pehuenche (1793-1803)}

La mención que se hace en las fuentes a distintas agrupaciones pehuenches presentes en los parlamentos, provenientes desde diferentes puntos geográficos, revela la creciente importancia que fueron adquiriendo los pehuenches con el avance del siglo XVIII. El parlamento de Negrete en 1803 refleja esta importancia y mayor conocimiento de parte de los españoles. En el acta de dicho parlamento se aprecia, al final del documento, un cuadro donde se especifica la "relacion de los Caciques Governadores y particulares, con sus Respetados y Mozetones que han concurrido al Parlamento General de Negrete de los quatro Butalmapus" (Zavala Cepeda 2015: 423, Tabla 2). En dicho esquema se anotaron los datos de cada uno de los vutanmapu, las parcialidades que los conformaban, quiénes eran sus representantes y cuántas personas de cada parcialidad se encontraban presentes en el parlamento, en un recuento demográfico 
bastante completo. Estos datos, en especial los referentes al vutanmapu pehuenche, indican que despuntando el siglo XIX las distintas agrupaciones pehuenches mencionadas en los encuentros del siglo XVIII estaban acudiendo de manera regular a los parlamentos y se habían ido incorporando a las dinámicas fronterizas que permitieron el desarrollo de las relaciones hispano-pehuenches que se han ido desglosando en este trabajo.

\section{Discusión}

El análisis de la participación de los pehuenches en los actos parlamentarios permite apreciar su inserción en una dinámica interétnica fronteriza que solía desenvolverse en los valles occidentales, pero que por medio de la conjunción entre la mirada al oriente de las autoridades coloniales y las estrategias sociopolíticas pehuenches, se amplió el escenario de desarrollo de dicha dinámica fronteriza en el siglo XVIII. Este escenario ampliado en el cual los pehuenches fueron actores principales a partir del parlamento de Negrete de 1771, fue propiciado en parte por las estrategias culturales que desplegaron estas comunidades indígenas como respuesta al intento de sujeción espiritual y material por parte de los representantes de la Corona española. Sin embargo, es difícil definir el tipo de relación hispano-pehuenche durante el período analizado, puesto que transitó entre acuerdos y conflictos (p. ej. Bechis 2008, Zavala Cepeda 2008). La organización sociopolítica de los grupos indígenas cordilleranos (dentro de los cuales se cuentan los pehuenches) consistía en un poder descentralizado a modo de sociedades segmentarias unidas por linaje (Sahlins 1972: 81 y ss.) con liderazgos muy acotados, por lo que era común que una parcialidad indígena haya estado en paz al mismo tiempo que otra sostenía algún tipo de acción belicosa contra los españoles u otros grupos étnicos (Zavala Cepeda 2007), tal como se refleja en la siguiente cita del acta de Santiago en 1782: "la divercidad de Naciones, y la oposicion que tienen entre si, es causa de que la tranquilidad en unas no sea transcendental à todas" (Zavala Cepeda 2015: 337). De tal manera que la complejidad de las relaciones interétnicas de la frontera del Biobío durante el siglo XVIII Ilevó a que los pehuenches sostuvieran conflictos entre sí; otras -no menos numerosas- con las comunidades indígenas vallunas; además de los problemas que surgían cada cierto tiempo con los españoles. No obstante, también existieron alianzas entre los grupos cordilleranos y otras agrupaciones indígenas, a la vez que con los hispanocriollos. Como reflejo de la creciente importancia estratégica y política que significaron los grupos pehuenches del siglo XVIII, es posible apreciar la realización de parlamentos exclusivos con los representantes de la "Nación Pehuenche" (siguiendo a Bechis 2008) concentrados hacia la segunda mitad de dicho siglo: Laja en 1756, San Carlos en 1783 y Chillán en 1798.

En definitiva, lo que se interpreta de los documentos analizados es una realidad política y social que se movía en dos planos diferentes: los acuerdos y promesas de evitar los conflictos por ambos bandos y entre autoridades, aunque, en paralelo se realizaban constantes malocas contra las haciendas hispanocriollas, enmarcadas en las necesidades económicas de las comunidades indígenas involucradas. Estos dos planos convergían en algún punto, ya que luego de las constantes correrías en ambas direcciones se generaba la necesidad de controlar estos hechos, por lo que se estipulaban como temas 
a tratar en las instancias parlamentarias, donde las respectivas autoridades y representantes de cada sociedad se comprometían a acabar con ellas, junto con una aparente sumisión indígena al intento de reducción a pueblos y evangelización, lo cual no era llevado a la práctica más que puntualmente y por intereses creados. Esta dinámica conflictos/acuerdos se fue reproduciendo una y otra vez durante el período analizado, generando transferencias culturales en todo el ámbito fronterizo.

\subsection{Particularidad pehuenche}

Como se mencionó previamente, los grupos étnicos constituyen categorías de adscripción e identificación que pueden ser dadas tanto por los propios actores sociales como por voces externas a ellos. En este sentido es importante aclarar que por medio de las fuentes consultadas no fue posible acceder a una autodefinición pehuenche respecto de sí mismos, aunque sí a la visión externa sobre dichos grupos. De esta manera, se observó que los grupos denominados pehuenches eran distinguidos por los españoles como una entidad diferente al resto de los pueblos indígenas fronterizos, especialmente de los provenientes de la Araucanía, aunque compartía con estos últimos rasgos culturales, propio de una dinámica de transferencias culturales. Ejemplo de esta diferenciación es un fragmento del acta de Lonquilmo en 1784, cuando se hace mención a los pehuenches incluyéndolos dentro del mismo vutanmapu junto a,

Puelches y Yndios Pampas que poseen los Paises a la parte septentrional del Reyno desde Malalgue y Fronteras de Mendoza, hasta el Mamilmapu situado en las Pampas de Buenos Ayres (...) formando un cuerpo y parcialidad con nuestros Puelches y Pehuenches de Maule Chillan, y Antuco (Zavala Cepeda 2015: 354).
Aunque sin duda que el principal aspecto que particularizó el comportamiento pehuenche en el mundo fronterizo del Biobío fue su movilidad. Esta característica de un grupo humano es posible asociarla a inestabilidad social, pero a la vez se vincula a los aspectos más dinámicos de la economía (Augé 2007: 31). De hecho, mediante la revisión de antecedentes y análisis de las fuentes es posible apreciar esta doble condición de inestabilidad y dinamismo entre los grupos pehuenches, características que habrían implicado una contradicción entre lo esperado y lo puesto en práctica por las autoridades coloniales, en el sentido que, por un lado las fuentes de la época dan cuenta del intento por reducir a pueblos a los pehuenches. Pero, por otro lado, la alta movilidad de los indígenas cordilleranos era la base de la alianza hispano-pehuenche, ya que a través de ellos podían acceder a determinados recursos que transaban en el amplio circuito comercial del cono sur americano y hacer frente a los huilliches y pampas, quienes asaltaban las haciendas hispanocriollas fronterizas mediante constantes malocas. Esta misma inestabilidad en cuanto a los espacios ocupados, debido a la constante movilidad, afectó el intento hispano por convertir a los pehuenches al cristianismo, haciendo fracasar otra de las políticas coloniales en este territorio: la de evangelización.

\subsection{Relaciones interétnicas}

Para finalizar esta discusión, es válido preguntarse si existió un cambio en las políticas de la Corona española respecto a las formas de conquista a implementar sobre los grupos indígenas de la frontera del Biobío, o si el cambio en las relaciones hispano-indígenas verificado en los cinco momentos distinguidos surgió como fruto de reestructuraciones internas 
de la sociedad indígena y afectó el devenir de las relaciones interétnicas. Antes de esbozar una respuesta, es importante destacar que las dinámicas interétnicas pehuenches previas a 1726 se caracterizaban por constantes conflictos tanto con otros grupos indígenas como con los hacendados hispanocriollos que ocupaban la zona fronteriza, tanto hacia occidente como oriente de la cordillera de los Andes. Además, el conocimiento temprano sobre las costumbres de los habitantes de la cordillera viene a partir de escasos relatos de cronistas, aventureros y autoridades de los siglos XVI y XVII (p. ej. Bibar 1966 [1558]; Núñez de Pineda 1863 [1673]; AGI, Chile, Vol. $26^{13}$ ), quienes ponen énfasis en el carácter móvil, baja composición demográfica, sustentación mediante la caza y recolección y constantes correrías a sus vecinos ganaderos y agricultores por parte de los pehuenches. En dichos documentos pre-siglo XVIII, estos grupos sociales aún son registrados de manera homogénea, sin mayores distinciones sobre sus distintas proveniencias geográficas y relaciones con el mundo colonial. En este sentido, podríamos adscribir a dichas comunidades históricas dentro de lo que el Sahlins (1972: 8486) ha denominado como clanes territoriales, apreciándose un cambio en la organización sociopolítica pehuenche a lo largo del tiempo entre los momentos previos y posteriores a 1726.

En concreto se propone que este nuevo escenario sociopolítico se dio como una confluencia de intereses entre ambas sociedades. Por ejemplo, en el citado artículo 5 del parlamento de Lonquilmo de 1784 se indicaba que los pehuenches avanzaban por los boquetes y pasos cordilleranos con "frutos

Archivo General de Indias (AGI), Chile, Vol. 26, R1, N2. Carta del gobernador de Chile, Tomás Marín de Poveda al Rey de España, 4 de mayo de 1697. que produsen sus tierras" a comerciarlos con los españoles (Zavala Cepeda 2015: 355). Ante esta situación, los dirigentes coloniales instaban a los encargados de asegurar la frontera que permitieran el paso de los pehuenches y sus productos, a intercambiar en comercio recíprocamente ventajoso y bajo la excusa de evitar que estos grupos protagonizaran malocas contra las haciendas hispanas de la Pampa.

Desde la perspectiva indígena, una de las expresiones más nítidas de la reestructuración político-económica de las agrupaciones fronterizas fue la instalación mapuche en territorio trasandino, lo que implicó la constitución de vastas redes de intercambio y de alianzas políticas interétnicas en el siglo XVIII. Además, por causa de estos procesos de desplazamientos físicos y reacomodos sociales, surgieron inevitablemente conflictos interindígenas (Boccara 2007: 328). Todo esto podría estar evidenciando que durante el período en que se centra esta investigación, los grupos pehuenches habrían desarrollado un proceso dinámico de respuesta a las transferencias culturales en que se enmarcaron los cambios evidenciados en los cinco momentos propuestos.

\section{Conclusiones}

Se sostiene que las parcialidades cordilleranas, particularmente los grupos pehuenches, se habrían diferenciado conductualmente del resto de los grupos étnicos participantes de la historia fronteriza del Biobío en el siglo XVIII, con quienes si bien compartían códigos culturales, aparecen con mucha más fuerza en las fuentes de la época justamente por su creciente protagonismo en la dinámica social imperante hacia las últimas décadas del período 
colonial. Lo que hicieron dichas agrupaciones fue aprovechar su acabado conocimiento de las rutas y pasos transcordilleranos, manteniendo un modo de vida móvil que les permitía explotar recursos tales como sal y ganado, los que se encontraban dentro de sus circuitos de circulación. Junto a esto, algunos representantes pehuenches aprovecharon las instancias de evangelización por parte de las misiones religiosas como otra manera de generar alianzas con los españoles, aunque sin modificar estructuralmente sus conductas. A su vez, las autoridades coloniales notaron que eran los pehuenches quienes articulaban las rutas a seguir tras los recursos, además que disputaban los territorios con parcialidades que generaban grandes pérdidas a las haciendas fronterizas mediante las malocas (huilliches y pampas), por lo que buscaron generar alianzas con ellos y comenzaron a mirar hacia el oriente de la Araucanía, especialmente a partir de las últimas décadas del siglo XVIII. Además, a causa de la participación pehuenche en una dinámica fronteriza extra-araucana, con contactos y desplazamientos permanentes hacia el oriente de los Andes, se generó la necesidad de acercamiento con la sociedad hispanocriolla, desplegando para este fin estrategias políticas y socioculturales que pueden verse reflejadas en la secuencia histórica de las relaciones hispano-pehuenches a lo largo del siglo XVIII. De esta manera se observó el paso desde una relación caracterizada por las constantes malocas realizadas por los pehuenches sobre los asentamientos hispanocriollos hacia un fuerte vínculo de alianza entre españoles y pehuenches, aunque matizado por la presencia de distintos "tipos" de pehuenches, los que se comportaban de diferentes maneras frente a las autoridades hispanas, generando alianzas interétnicas según las necesidades de sus líderes. Por lo tanto, si bien existen otros posibles análisis en torno a las relaciones hispano-pehuenches en el siglo XVIII (muchos de los cuales ya se han realizado), este trabajo pretende aportar a una línea investigativa que plantea problemáticas históricas y las analiza desde la perspectiva de las relaciones interétnicas, en este caso de manera particular sobre la participación de los pehuenches en la frontera del Biobío a la luz de lo manifestado -explícita e implícitamente- en las actas de los parlamentos coloniales hispano-indígenas.

\section{Agradecimientos}

Comprometen la gratitud del autor, en primer lugar, el profesor José Manuel Zavala Cepeda, investigador responsable del proyecto FONDECYT No 1120857 "Expresión y presencia del otro en la frontera araucana: inscripciones mapuches e hispanas en lugares y en relatos de parlamentos de tres área de la Araucanía colonial, 1605-1803", en el cual se enmarcó la investigación que dio origen al presente artículo. En segundo lugar, a los revisores anónimos que gracias a sus valiosos comentarios ayudaron a mejorar la versión original del presente escrito. Por último, agradezco a Ana María Bardeci y Salomé Fernández por sus desinteresadas ayudas bibliográficas a distancia. 


\section{Bibliografía}

Abercrombie, T. 1991. "Articulación doble y etnogénesis". Reproducción y transformación de las sociedades andinas, siglo XVI-XX. S. Moreno y F. Salomon (Eds.). Quito: Ediciones AbyaYala. 197-212.

Augé, M. 2007. Por una antropología de la movilidad. Barcelona: Editorial Gedisa.

Barth, F. 1969. Ethnic groups and boundaries. Boston: Little, Brown and Company.

Bechis, M. 2008. La participación de la Capitanía General de Chile y del Virreinato de Río de la Plata en la génesis de la 'Nacion Pehuenche'. Piezas de Etnohistoria del Sur Sudamericano. Martha Bechis. Madrid: Consejo Superior de Investigaciones Científicas. 141-164.

Bello, A. 2011. Nampülkafe: el viaje de los mapuches de la Araucanía a las pampas argentinas. Territorio, política y cultura en los siglos XIX y XX. Temuco: Ediciones Universidad Católica de Temuco.

Bibar, G. 1966 [1558]. Crónica y relación copiosa y verdadera de los reinos de Chile. Santiago: Fondo Histórico y Bibliográfico José Toribio Medina.

Boccara, G. 2005. "Génesis y estructura de los complejos fronterizos euro-indígenas. Repensando los márgenes americanos a partir (y más allá) de la obra de Nathan Wachtel". Memoria Americana 13: 21-52.

2007. Los vencedores. Historia del pueblo mapuche en la época colonial. Santiago: Universidad Católica del Norte, Línea editorial IIAM, Ocho Libro editores.

De la Cruz, L. 1953 [1806]. "Tratado importante para el conocimiento de los indios pehuenches según el orden de su vida". Revista Universitaria XXXVIII (1): 29-59.

Espiñeira, P. 1990 [1758]. "Relación del viaje y misión a los pehuenches, 1758". Misioneros en la Araucanía, 1600-1900, Vol. II: Documentos. J. Pinto Rodríguez (Ed.). Bogotá: CELAM. 3-34.

Goicovich, F. 2004. Reevaluación etnohistórica de las ayllareguas reche-mapuches. Actas del V Congreso Chileno de Antropología: 559-565.

Havestadt, B. 1990 [1777]. "Chilidugu o tratado de la lengua chilena: VII parte: diario de la misión entre los indios chilenos, 1752". Misioneros en la Araucanía, 1600-1900, Vol. II: Documentos. J. Pinto Rodríguez (Ed.). Bogotá: CELAM. 35-84.

Lázaro, C. 2002. "El parlamentarismo fronterizo en la Araucanía y las Pampas". Colonización, resistencia y mestizaje en las Américas (siglos XVI-XX). G. Boccara (Ed.). Quito: Ediciones Abya-Yala. 201-235.

León Solís, L. 1991. Maloqueros y conchavadores en Araucanía y las Pampas, 1700-1800. Temuco: Ediciones Universidad de la Frontera.

2001. Los señores de las cordilleras y las pampas. Los pehuenches de Malalhue, 1770-1800. Mendoza: Universidad de Congreso.

León Solís, L., Silva, O. y Téllez, E. 1997. "La guerra contra el malón en Chile, Cuyo y Buenos Aires, 1750-1800". Cuadernos de Historia 17: 7-67.

Mandrini, R. y Ortelli, S. 2002. "Los 'Araucanos' en las Pampas". Colonización, resistencia y mestizaje en las Américas (siglos XVI$X X)$. G. Boccara (Ed.). Quito: Ediciones Abya-Yala. 237-257.

Méndez, L. M. 1982. "La organización de los parlamentos de indios en el siglo XVIII". Relaciones fronterizas en la Araucanía. S. Villalobos, C. Aldunate, H. Zapater, L. M. Méndez y C. Bascuñán (Eds.). Santiago: Ediciones de la Universidad Católica de Chile 107-173.

Núñez de Pineda y Bascuñán, F. 1863 [1673]. Cautiverio feliz, y razón de las guerras dilatadas de Chile. Colección de historiadores de Chile y documentos relativos a la historia nacional, tomo III. Santiago: Imprenta del Ferrocarril.

Orellana, M. 1992. Historia y Antropología de la isla de la Laja. Santiago: Editorial Universitaria.

Pinto Rodríguez, J. 2003. La formación del Estado y la Nación, y el pueblo mapuche. De la inclusión a la exclusión. Santiago: Ediciones DIBAM.

Sahlins, M. 1972. Las sociedades tribales. Barcelona: Editorial Labor S.A.

Silva, O. 2005. "Alianzas bélicas y divisiones territoriales mapuches entre los siglos XVI y XVIII". Cuadernos de Historia 24: 31-65.

Silva, O. y Téllez, E. 1993. "Los pewenche: identidad y configuración de un mosaico étnico colonial”. Cuadernos de Historia 13: 7-54.

Toro, O. 2015. Las estrategias culturales pehuenches en los parlamentos del siglo XVIII. Los espacios de diferenciación sociocultural en la frontera del Biobío. Tesis de Magister. Santiago: Universidad de Chile.

Turgeon, L. 1996. "De I' acculturation aux transferts culturels". Transferts culturels et métissages. Amérique/Europe, XVleXXe siècle. L. Turgeon, D. Dêlage y R. Ouellett (Eds.). París: L' Harmattan. 11-32.

Valenzuela, J. 2008. "Los boquetes cordilleranos como espacios de transculturación". La circulación en el Mundo Andino, 1760-1860. T. Pereira y A. Ibáñez (Eds.). Santiago: Alfabeta Artes Gráficas. 81-117.

Varela, G., Font L. M. y Cúneo, E. 1997. "Los pehuenche del noroeste de Neuquén y sus relaciones fronterizas en la segunda mitad del siglo XVIII". Historia Indígena 2: 77-95.

Vergara, J. 2005. La herencia colonial del Leviatán. El Estado y los mapuche-huilliches (1750-1881). Iquique: Ediciones Instituto de Estudios Andinos, Universidad Arturo Prat, pp. 89-107.

Villalobos, S. 1982. "Tres siglos y medio de vida fronteriza". Relaciones fronterizas en la Araucanía. S. Villalobos, C. Aldunate, H. Zapater, L. M. Méndez y C. Bascuñán (Eds.). Santiago: Ediciones de la Universidad Católica de Chile. 9-64 1989. Los pehuenches en la vida fronteriza. Santiago: Ediciones de la Universidad Católica de Chile. 
1995. "Las relaciones fronterizas". Vida fronteriza en la Araucanía. El mito de la guerra de Arauco. Santiago: Editorial Andrés Bello. 117-154.

Villar, D. y Jiménez, J. 2000. "Botín, materialización ideológica y guerra en las pampas, durante la segunda mitad del siglo XVIII. El caso de Llanketruz". Revista de Indias LX (220): 687-707.

Zavala Cepeda, J.M. 2007. "Teoría y práctica indígenas de la guerra en las fronteras de la América hispánica del siglo XVIII: el caso de los mapuche o araucanos". Propaganda y mentalidad bélica en España y América durante el siglo XVIII. D. González Cruz
(Ed.). Madrid: Editorial Ministerio de Defensa de España. 95-119 . 2008. Los mapuche del siglo XVIII. Dinámica interétnica y estrategias de resistencia. Santiago: Editorial Universidad Bolivariana S.A.

. 2012. "La presencia mapuche en los Andes según las fuentes coloniales chilenas". Revista de Estudios Trasandinos 17 (1): $119-134$

2015. Los parlamentos hispano-mapuches, 15931803: textos fundamentales. Zavala Cepeda, J. M. (Ed.). Temuco: Ediciones Universidad Católica de Temuco. 